\title{
The persistence and ecological impacts of a cyanobacterium genetically engineered to express mosquitocidal Bacillus thuringiensis toxins
}

\author{
Irene Ketseoglou and Gustav Bouwer
}

\begin{abstract}
Background: The cyanobacterium Anabaena PCC $7120 \# 11$ has been genetically engineered to act as a delivery vehicle for Bacillus thuringiensis subspecies israelensis mosquitocidal toxins. To address ecological concerns about releasing this genetically engineered microorganism into the environment for mosquito larva control, the persistence and ecological impacts of PCC 7120\#11 was evaluated using multi-species, standardized aquatic microcosms.

Methods: The microcosms were set up as described in ASTM E1366-02 (Standard Practice for Standardized Aquatic Microcosms: Fresh Water), with a few modifications. The treatment group microcosms were inoculated with PCC $7120 \# 11$ and key water quality parameters and non-target effects were compared between the treatment and control groups over a period of 35 days.

Results: PCC $7120 \# 11$ decreased from a concentration of $4.50 \times 10^{6} \mathrm{cell} / \mathrm{s} / \mathrm{ml}$ (at inoculation) to $1.32 \times 10^{3} \mathrm{cell} / \mathrm{s} / \mathrm{ml}$ after 4 weeks and larvicidal activity against third instar larvae of Anopheles arabiensis was only evident for two weeks after treatment. Both treatment and the interaction of treatment and time had a significant effect on nitrate, phosphate and photosynthetic microorganism concentrations. Treatment with PCC 7120\#11 caused a temporary spike in ammonia in the microcosms a week after treatment, but the concentrations were well below acute and chronic criteria values for ammonia in freshwater ecosystems. Cyprinotus vidua concentrations were not significantly different between PCC 7120\#11 and control microcosms. In PCC 7120\#11 microcosms, Daphnia pulex concentrations were significantly lower than control concentrations between days 18 and 25. By the end of the experiment, none of the measured variables were significantly different between the treatment groups.

Conclusions: The standard aquatic microcosm experiments provided more data on the ecological impacts of PCC 7120\#11 than single-organism assessments would have. On the basis of the relatively minor, short-term effects that PCC 7120\#11 had on water quality parameters and non-target invertebrates, further evaluation of PCC 7120\#11 for use in integrated vector management is warranted.
\end{abstract}

Keywords: Anabaena PCC 7120, Bacillus thuringiensis israelensis, Anopheles arabiensis, Genetically modified organism, Cry proteins, Microcosms, Non-target organisms

* Correspondence: gustav.bouwer@wits.ac.za

School of Molecular and Cell Biology, University of the Witwatersrand, ,

Private Bag 3, Wits, 2050 Johannesburg, South Africa 


\section{Background}

Bacillus thuringiensis subspecies israelensis (Bti) is a spore-forming, aerobic, gram-positive bacterium that produces crystalline inclusions that contain Cry (crystal) or Cyt (cytolytic) proteins that are toxic to nematoceran larvae [1]. Cry and Cyt proteins are pore-forming toxins that act on the midgut epithelial cells [2].

Mosquitoes play a major role in the transmission of malaria and other diseases, such as the Zika virus disease $[3,4]$. Biological control offers an environmentally lowimpact method for the control of mosquito larvae and provides another tool for use in integrated vector management (IVM), which is becoming increasingly reliant on successfully managing insecticide resistance [5]. Although Bti and formulations of Bti have been moderately successful as vector control agents (e.g. [6, 7]), they do not exhibit long-term larvicidal activity in the environment and may thus require frequent treatments for sustained vector control [8-10]. In an attempt to overcome the limitations of Bti as a larvicidal agent, microorganisms have been genetically engineered with the aim of producing Bti-based control agents that persist longer in the environment $[8,11]$.

The cyanobacterium, Anabaena sp. strain PCC 7120 (hereafter referred to as PCC 7120), is a filamentous, nitrogen-fixing cyanobacterium capable of multiplying in mosquito oviposition sites and maintaining its position in the water column $[8,9]$, thereby making it a suitable candidate for genetic engineering for use as a mosquito control agent. Furthermore, unlike some species of cyanobacteria, PCC 7120 is not considered toxic [12], and is unlikely to affect humans or animals. As a result of its suitable characteristics, PCC 7120 was genetically engineered to act as a delivery vehicle for Bti toxins. The cry $4 A a, c r y 11 A a$, and $p 20$ genes from Bti were introduced into PCC 7120 using an Escherichia coli-Anabaena shuttle vector pRL488p [13]. The resultant clone, PCC 7120\#11, has been shown in laboratory assays to be highly larvicidal to Aedes aegypti $[9,13]$, and several important malaria-carrying vectors such as Anopheles gambiae, Anopheles arabiensis, and Anopheles merus $[14,15]$. The Bti genes, which are under the control of two tandem promoters (cyanobacterial constitutive promoter, $P_{p s b A}$, and $E$. coli T7 early promoter, $P_{A 1}$ ), are integrated into the chromosome of PCC 7120\#11, resulting in a stable recombinant strain [15].

Although response surface methodology experiments have shown that PCC $7120 \# 11$ can be efficiently produced in photobioreactors [16], there are potential risks with large-scale releases of genetically engineered microorganisms (GEMs) in the field [8, 17, 18]. Due to the concerns of testing PCC 7120\#11 in the field and the difficulty in obtaining regulatory approval for field trials of GEMs, laboratory aquatic microcosms are the most feasible method of testing GEMs that are ultimately intended for application to natural waterbodies. Of particular interest in this study was the use of a multispecies system, the standardized aquatic microcosm (SAM), to evaluate the persistence and ecological impacts of PCC 7120\#11.

The SAM method is a simple and reliable method that mimics a generalized aquatic community, with important ecological processes, such as primary and secondary production, being demonstrated [19, 20]. The microcosms are standardized in that the experiment is initiated with the same chemically defined medium and sediment, same species assemblage and concentration of invertebrate species and photosynthetic microorganisms (PMs) [20, 21]. This allows for repeatability within a laboratory and between laboratories [21]. Although SAM experiments are more complex than single-species tests, they are not as complex as natural environments and thus reduce the likelihood that taxonomic uncertainties will occur [21]. Another advantage of the SAM protocol is that the experiments can be conducted and initiated at any time of the year [21].

As part of an assessment of the usefulness of PCC 7120\#11 in IVM, we evaluated the effects of PCC $7120 \# 11$ on a target organism (An. arabiensis) and ecotoxicology test organisms using the SAM system. Anopheles arabiensis was selected as the target organism since it is the most widespread vector of malaria in southern Africa [22]. Cladocerans, ostracods, and rotifers are useful and important aquatic ecotoxicology test organisms [23-25], and the SAMs used in this study included representatives of each of these metazoan groups. Since the metazoans in the SAMs are able to ingest filamentous cyanobacteria (e.g. [26, 27]), the SAMs would facilitate detection of any direct toxicity mediated by the larvicidal Bti proteins expressed in PCC 7120\#11. The SAMs also enable detection of indirect effects, such as changes in growth rates due to changes in the preferred food sources of an organism. To the best of our knowledge, this is the first study to assess the persistence and ecological impacts of a genetically engineered cyanobacterium using SAMs.

\section{Methods}

\section{Microcosms}

The microcosms were set up as described in ASTM E1366-02 Standard Practice for Standardized Aquatic Microcosms: Fresh Water [28], with a few modifications. The SAMs were kept in a growth room that was set at $21 \pm 1{ }^{\circ} \mathrm{C}$. Cool white lights were used for illumination (4700 lx; approximately $63 \mu \mathrm{mol} \mathrm{m} \mathrm{m}^{-2} \mathrm{~s}^{-1}$ photosynthetic photon flux density) with a L:D 12:12 h photoperiod.

The microcosm setup is described briefly. The microcosms consisted of sterile glass jars $(4 \mathrm{l})$ containing $3 \mathrm{l}$ 
of autoclaved chemically defined medium (T82MV) [28]. Autoclaved silica sand enriched with chitin and cellulose powder was added to the glass jars. Six jars (replicates) were allocated for PCC 7120\#11 and six jars (replicates) for the control, with an additional five prepared in case of breakages within the first week [28]. The glass jars were covered individually with square glass plates to minimize contamination and evaporation. Nine different species of photosynthetic microorganisms (PMs), which included algal and cyanobacterial species, were added to the jars on day 0 (start of the microcosms) and four species of invertebrates were added on day 4. After 7 days, quality control was performed to ensure the well-being of the communities in the microcosms [28]. On day 7 , PCC $7120 \# 11$ was added to PCC $7120 \# 11$ microcosms to produce an in-microcosm PCC $7120 \# 11$ concentration of $4.5 \times 10^{6}$ cells $/ \mathrm{ml}$. The organism abundance (PMs and invertebrates) and inorganic nutrient concentrations were measured twice a week.

\section{Culturing of PMs}

Anabaena cylindrica, Ankistrodesmus sp., Chlamydomonas reinhardtii, Chlorella vulgaris, Oscillatoria simplicissima, Scenedesmus obliquus, Raphidocelis subcapitata (syn. Selenastrum capricornutum), Stigeoclonium sp., and Ulothrix sp., were purchased from the University of Texas (UT) Algal Culture Collection. The PMs were cultured under continuous illumination (2000 lx; approximately $27 \mu \mathrm{mol} \mathrm{m} \mathrm{m}^{-2} \mathrm{~s}^{-1}$ photosynthetic photon flux density) at $25^{\circ} \mathrm{C}$, in individual 11 Erlenmeyer flasks containing sterile T82MV medium [20]. The cells were counted using a Palmer cell and were added to the microcosms at a concentration of $5 \times 10^{3}$ cells $/ \mathrm{ml}$. Filamentous PMs or PMs that tended to form clumps were, prior to counting and before being added to the microcosms, vigorously shaken in sterile jars with sterile glass beads [28]. The concentrations were calculated using the equation presented in the ASTM E1366-02 protocol [28].

\section{Culturing of non-target invertebrates}

Daphnia pulex (obtained from colonies at the Department of Water Affairs, Pretoria, South Africa) was cultured in sterile $3 \mathrm{l}$ glass jars containing sterile hard water (123 mg/l MgSO $; 96 \mathrm{mg} / \mathrm{l} \mathrm{NaHCO}{ }_{3} ; 4.0 \mathrm{mg} / \mathrm{l} \mathrm{KCl}$; $60 \mathrm{mg} / \mathrm{l} \mathrm{CaSO}{ }_{4} \cdot 2 \mathrm{H}_{2} \mathrm{O}$ ). Daphnids were cultured at $18{ }^{\circ} \mathrm{C}$ with a $\mathrm{L}: \mathrm{D}$ 18:6 $\mathrm{h}$ photoperiod and were fed a 1:1:1 mixture of yeast, fish food $\left(\right.$ TetraMin $\left.^{\circ}\right)$, and alfalfa (Mpho Khumalo, pers. comm.). The cultures were fed three times a week and sub-cultured every 2 weeks to avoid over-population. Sixteen D. pulex (three adults, three adults with eggs, and ten small) were added to each of the microcosm jars on day 4 [28]. Although the standard SAM setup includes the amphipod crustacean Hyalella azteca [28], we did not include this organism in our SAMs because, in contrast to its status in North America, it is not an important crustacean in South Africa.

The ostracod, Cypridopsis vidua was cultured in sterile glass beakers $(500 \mathrm{ml})$ containing sterile T82MV medium [20]. Ostracods were cultured at $18{ }^{\circ} \mathrm{C}$ with a $\mathrm{L}: \mathrm{D}$ 18:6 $\mathrm{h}$ photoperiod and fed weekly with a mixture of Stigeoclonium sp. and C. vulgaris cultures [28]. On day 4 of the experiment, C. vidua were removed from the beakers, rinsed in sterile T82MV medium, and then added to each microcosm jar (six ostracods per jar) [28].

The protozoans (Coleps sp.) and the rotifers (Lepadella sp.) were cultured in Petri dishes containing T82MV medium, yeast, and $C$. vulgaris. They were cultured at $25{ }^{\circ} \mathrm{C}$ under L:D 12:12 h photoperiods. Three hundred protozoans and 90 rotifers were added to each microcosm jar on day 4 of the experiment [28].

\section{Mosquitocidal activity of PCC $7120 \# 11$}

Third instar An. arabiensis larvae were obtained from colonies (origin: Kanyemba, Zimbabwe; colony name: KGB) maintained at the National Institute of Communicable Diseases (NICD) in Johannesburg, South Africa. The larvae were reared at the NICD in a controlled environment of $25^{\circ} \mathrm{C}$, relative humidity of $60 \%$, and a L:D 12:12 h photoperiod with a $45 \mathrm{~min}$ dawn and dusk light regime.

The larvicidal activity of PCC $7120 \# 11$ in the PCC $7120 \# 11$ microcosms was determined by the weekly (starting on day 7) addition of 30 third instar larvae of An. arabiensis. The mortality of the larvae was recorded $24 \mathrm{~h}$ post-inoculation (p.i.), after which all larvae (dead or alive) were removed from each treatment microcosm. Larvae were added also to the control (no PCC 7120\#11) microcosms.

\section{Sample collection and analysis}

Sampling and measurement of organism abundances and other variables were performed twice a week on the same days of the week (Tuesdays and Fridays). As part of quality control procedures, the $\mathrm{pH}$ of each microcosm was monitored using a HI 9828 multi-parameter HANNA probe (HANNA Instruments, Rhode Island, USA). After the $\mathrm{pH}$ measurements, the microcosms were mixed using a sterile spatula and the sides of the jars were scraped as completely as possible with a sterile rubber spatula [28]. Samples $(20 \mathrm{ml})$ from the mixed microcosms were filtered through $0.45 \mu \mathrm{m}$ ( $25 \mathrm{~mm}$ diameter) cellulose acetate syringe filters (Sartorius Biotech, Göttingen, Germany). At some sampling times, the clogging of filters necessitated the use of more than one syringe filter per $20 \mathrm{ml}$ sample. The filtrates were analyzed for key water quality parameters using a Spectroquant ${ }^{\circ}$ NOVA 60 photometer (Merck, 
Darmstadt, Germany) and photometric Spectroquant ${ }^{\circ}$ test kits: $\mathrm{NO}_{3}-\mathrm{N}$ (kit 1.09713), $\mathrm{NO}_{2}-\mathrm{N}$ (kit 1.14776), $\mathrm{PO}_{4}-\mathrm{P}$ (kit 1.14848), and $\mathrm{NH}_{4}-\mathrm{N}$ (kit 1.14752; measures both ammonium ions and dissolved ammonia). Due to unforeseen circumstances, chemical analyses were not performed on day 32 of the experiments.

A sample $(4 \mathrm{ml})$ was removed from each of the mixed microcosms with $2 \mathrm{ml}$ being used for PM counts and $2 \mathrm{ml}$ used for Coleps sp. and Lepadella sp. counts. The PM counts were performed using a Palmer cell, examining a maximum of 65 fields of view [28]. The rotifers and protozoans were counted in $100 \mu \mathrm{l}$ aliquots in 96 well micro-titer plates, with a total of $2 \mathrm{ml}$ being evaluated [28]. Aliquots $(100 \mathrm{ml})$ of each stirred microcosm were removed (using a large-bore, dip sampler) for the D. pulex and C. vidua counts [28]. All aliquots were returned to the microcosms after the counting was performed.

\section{Statistical analysis}

Data were analyzed using the Mixed Models - Repeated Measures procedure of NCSS 10 Statistical Software (NCSS, LLC. Kaysville, Utah, USA). A longitudinal design was used, with one between-subjects factor (treatment) and one within-subjects factor (time). The AR(1) pattern was used for the variance-covariance structure, with selection of this pattern being supported by Akaike information criterion (AIC) model fit assessments. Counts were $\log$ transformed $\left[\log _{10}(x+1)\right]$, a transformation that is preferred when some of the observed values are small numbers or zero $[29,30]$. The denominator degrees of freedom for $F$ tests were computed using the Kenward and Roger adjustment [31], an adjustment proposed for small sample settings. When statistical analyses indicated that a factor or an interaction of factors had a significant effect on the response, data were analyzed further by post-hoc Bonferroni multiple comparison tests. Differences were considered significant at $\alpha=$ 0.05. Although treatment $\times$ time interactions may be considered most informative for this study, assessment of treatment as a main factor is useful for interpreting the results, especially in the absence of a significant treatment $\times$ time interaction for a response. The slopes of the growth curves of the metazoan organisms were analyzed using the linear regression model within the nonlinear regression module of GraphPad Prism version 6.05 for Windows (GraphPad Software, La Jolla, USA).

\section{Results}

\section{Time as a factor}

As expected, time had a significant effect $(P<0.0001)$ on each of the evaluated responses (water quality parameters and organism concentrations) and time as a main factor will not be discussed further. For each of the evaluated responses, the concentration curves (mean profile plots) for the control and PCC 7120\#11 microcosms were similar in shape (Figs. 1, 2 and 3), but for some responses there were significant interactions of treatment (PCC $7120 \# 11$ or control) and time. These interactions are discussed in more detail below.

\section{Nitrogen compounds}

Treatment, as a main factor, had a significant effect $\left(F_{(1,36.1)}=15.3921, P=0.0004\right)$ on nitrate $\left(\mathrm{NO}_{3}-\mathrm{N}\right)$ concentration, with the mean nitrate concentration being higher in the PCC 7120\#11 microcosms (3.21 mg/l) than in the control microcosms $(2.88 \mathrm{mg} / \mathrm{l})$. The treatment $\times$ time interaction was significant $\left(F_{(9,83.5)}=\right.$ 2.3985, $P=0.0180$ ) for nitrate concentration, with the nitrate concentration being significantly higher $(P<0.0001)$ in the PCC $7120 \# 11$ microcosms than in the control microcosms on day 18 (Fig. 1a).

The nitrite $\left(\mathrm{NO}_{2}-\mathrm{N}\right)$ concentration decreased from an initial concentration of approximately $0.66 \mathrm{mg} / \mathrm{l}$ to below $0.025 \mathrm{mg} / \mathrm{l}$ by day 18 and remained below $0.025 \mathrm{mg} / \mathrm{l}$ until the end of the experiment in both microcosm types (Fig. 1b). The treatment effect was not significant for nitrite concentration $\left(F_{(1,} 23.8\right)=$ $0.0816, P=0.7777)$, and there was no significant treatment $\times$ time interaction for nitrite concentration $\left(F_{(9,85.9)}=0.7794, P=0.6358\right)$.

The initial concentration of total ammonia nitrogen (TAN: $\mathrm{NH}_{4}-\mathrm{N}+\mathrm{NH}_{3}-\mathrm{N}$ ) was approximately $0.05 \mathrm{mg} / \mathrm{l}$ in both microcosm types (Fig. 1c). After day 28, the concentration of TAN in the microcosms increased rapidly and reached concentrations of between 1.8 and $2.0 \mathrm{mg} / \mathrm{l}$ by day 35 (Fig. 1c). The treatment $\times$ time interaction was not significant for TAN concentration $\left(F_{(9,66.6)}=0.4885\right.$, $P=0.8773)$, and there was no significant difference $\left(F_{(1,5.2)}=0.0080, P=0.9320\right)$ for TAN concentration between treatment groups.

\section{Phosphate}

The phosphate $\left(\mathrm{PO}_{4}-\mathrm{P}\right)$ concentration decreased after initiation of the experiments in both microcosm types (Fig. 1d), but between days 25 and 35 the phosphate concentration in the microcosms increased (Fig. 1d). Treatment had a significant effect on phosphate concentration $\left(F_{(1,8.9)}=7.8673, P=0.0208\right)$, with the mean phosphate concentration being higher in the PCC $7120 \# 11$ microcosms $(0.90 \mathrm{mg} / \mathrm{l})$ than in the control microcosms $(0.72 \mathrm{mg} / \mathrm{l})$. The treatment $\times$ time interaction was also significant $\left.\left(F_{(9,} \quad 79.4\right)=3.6865, \quad P=0.0007\right)$ (Fig. 1d).

\section{Photosynthetic microorganisms}

In the PCC $7120 \# 11$ microcosms, the PCC $7120 \# 11$ concentration decreased between days 7 and 14 but then 

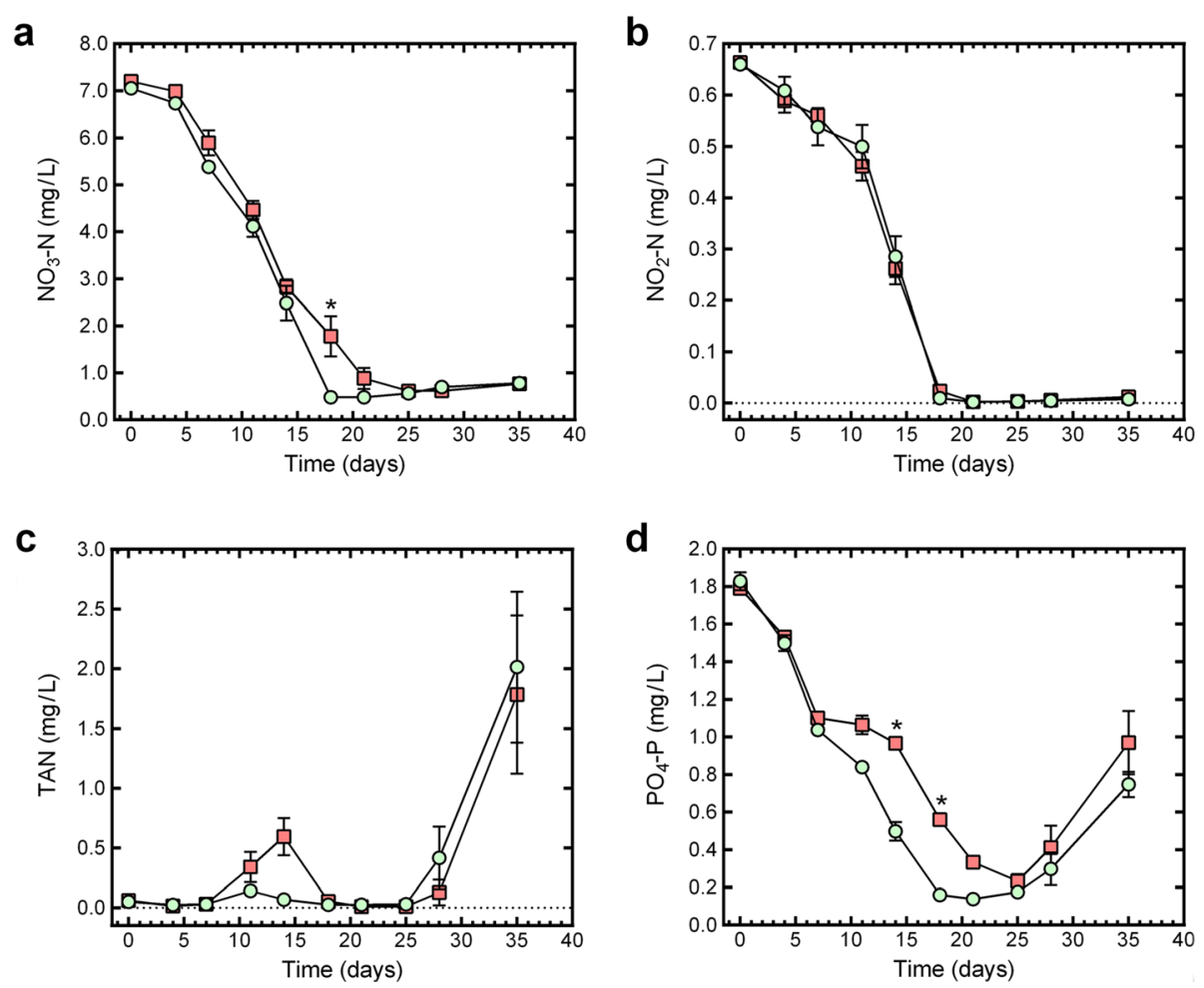

Fig. 1 The change in nitrate, nitrite, ammonia and phosphate concentration in control (light green circle) and PCC $7120 \# 11$ (red square) microcosms during the 35-day evaluation period. a $\mathrm{NO}_{3}-\mathrm{N} ; \mathbf{b} \mathrm{NO}_{2}-\mathrm{N}$; $\mathbf{c}$ total ammonia nitrogen (TAN); and $\mathbf{d} \mathrm{PO}_{4}-\mathrm{P}$. Data points show the mean \pm standard error of the mean, with an asterisk indicating a significant difference between the means of PCC $7120 \# 11$ and control microcosms on the evaluation day

remained relatively constant in the region of $4.5 \times 10^{5}$ cells/ml for 14 days (from day 14 to day 28) (Fig. 2a). By day 35 , the PCC $7120 \# 11$ concentration had decreased to approximately $1.32 \times 10^{3}$ cells $/ \mathrm{ml}$ (Fig. $2 \mathrm{a}$ ).

The main effect of treatment was significant for PM concentration $\left(F_{(1,13.2)}=4.9768, P=0.0437\right)$, with the mean PM concentration being higher in the PCC $7120 \# 11$ microcosms $\left(1.32 \times 10^{6}\right.$ cells $\left./ \mathrm{ml}\right)$ than in the control microcosms $\left(9.83 \times 10^{5}\right.$ cells $\left./ \mathrm{ml}\right)$. The treatment $\times$ time interaction was significant for PM concentration $\left(F_{(10,90.7)}=9.0738, P<0.0001\right)$, with the mean PM concentration on day 7 (the day of inoculation with PCC 7120\#11) in the PCC 7120\#11 microcosms being significantly higher $(P<0.0001)$ than that in the control microcosms (Fig. 2b). From the high of approximately $5.36 \times 10^{6}$ cells $/ \mathrm{ml}$ on day 7 , the PM concentration in the PCC $7120 \# 11$ microcosms decreased to approximately $2.48 \times 10^{6}$ cells $/ \mathrm{ml}$ by day 14 (Fig. $2 \mathrm{~b}$ ). After day 14 , the PM concentration curves had comparable profiles in the control and PCC 7120\#11 microcosms (Fig. 2b).

\section{Protozoans}

In both treatment groups, Coleps sp. populations increased rapidly from day 4 until day 14, then increased gradually to a maximum of approximately 250 Coleps/
mL by day 25 (Fig. 2c). The Coleps sp. concentrations in both microcosm types decreased gradually between days 25 and 35 (Fig. 2c). The treatment $\times$ time interaction was not significant for the Coleps sp. concentration $\left(F_{(9,80.7)}=0.4025, P=0.9303\right)$, but the main effect of treatment was significant for Coleps sp. concentration $\left(F_{(1,25.2)}=4.6167, P=0.0415\right)$, with the mean concentration being 51.3 Coleps $/ \mathrm{ml}$ and 60.8 Coleps $/ \mathrm{ml}$ for the control and PCC 7120\#11 microcosms, respectively.

\section{Cladocerans}

The D. pulex concentrations increased in an exponentiallike manner in both microcosm types (Fig. 3a), but after day 11 the $D$. pulex populations in the control microcosms increased more rapidly than the $D$. pulex populations in the PCC 7120\#11 microcosms (Fig. 3a). The treatment $\times$ time interaction was significant for $D$. pulex concentration $\left(F_{(9,87.8)}=2.2878, P=0.0234\right)$, with post-hoc tests showing that the mean $D$. pulex concentration in the PCC 7120\#11 microcosms was significantly lower than that in the control microcosms on day $18(P=0.0244)$ and day $25(P=0.0280)$. The slope $\left(0.098\right.$; adjusted $\left.r^{2}=0.754\right)$ of the $D$. pulex growth curve for the PCC 7120\#11 microcosms was significantly lower $\left(F_{(1,92)}=4.621, P=0.0342\right)$ than that of the control microcosms (slope $=0.122$; adjusted $r^{2}=0.828$ ) between day 4 and day 28 (the apparent 

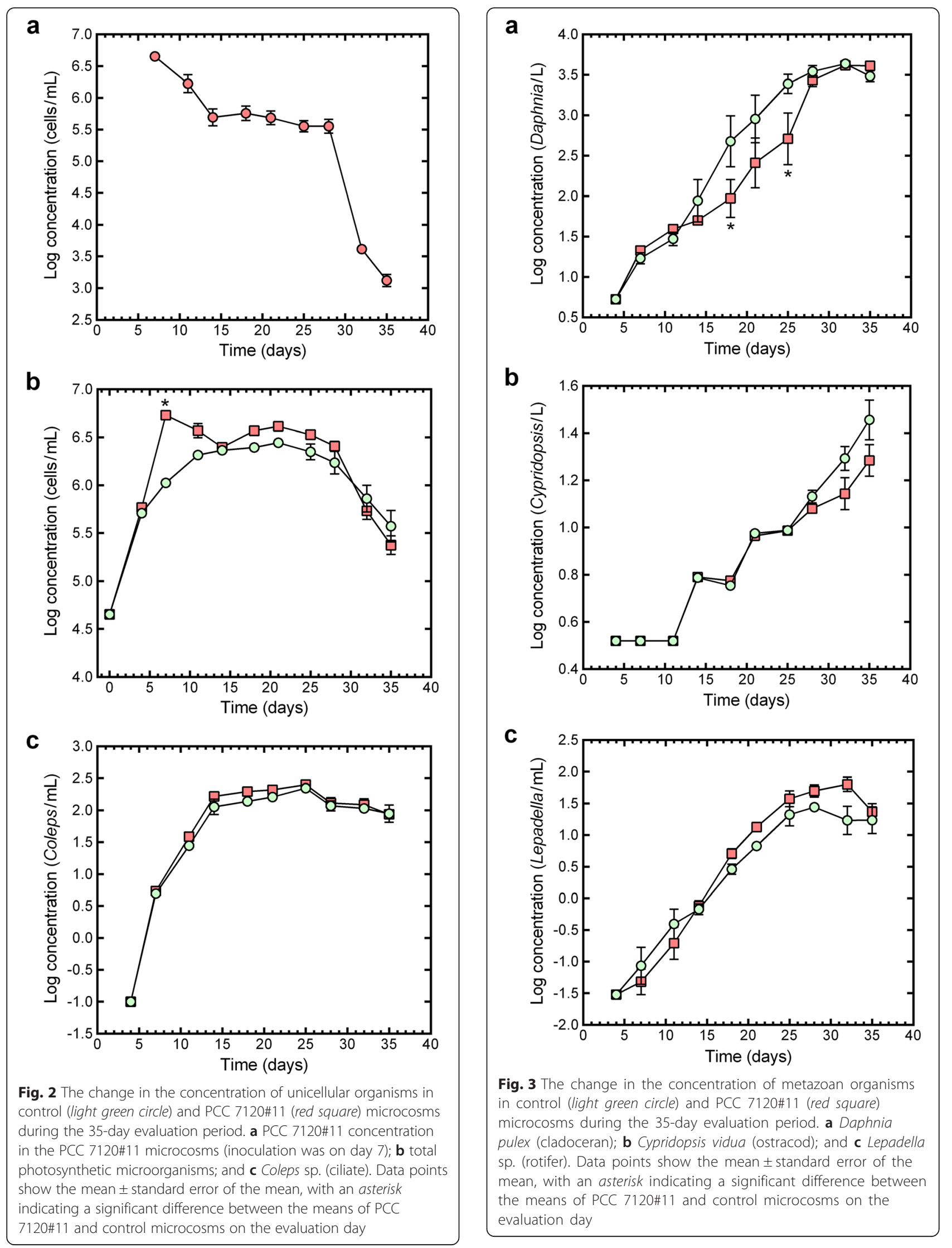
exponential growth phase). By day 32, D. pulex populations in the two types of microcosms had peaked at comparable concentrations (Fig. 3a), and treatment (as a main factor) did not have a significant effect on the concentration of D. pulex $\left(F_{(1,19.5)}=2.3399, P=0.1421\right)$.

\section{Ostracods}

The mean profile plots for C. vidua concentrations had similarly-shaped profiles in the control and PCC 7120\#11 microcosms (Fig. 3b), with C. vidua populations exhibiting a lag phase from day 4 to day 11 . The $C$. vidua population growth between days 11 and 25 was characterized by alternating periods of growth and nogrowth plateaus (Fig. $3 \mathrm{~b}$ ). The treatment $\times$ time interaction was not significant for $C$. vidua concentration $\left(F_{(9,75.6)}=1.3300, P=0.2360\right)$, and treatment (as a main factor) also did not have a significant effect on $C$. vidua concentration $\left(F_{(1,10.3)}=1.9715, P=0.1896\right)$.

\section{Rotifers}

For both treatment groups, Lepadella sp. growth was characterized by exponential-like growth between days 4 and 25 (Fig. 3c). The peak Lepadella sp. concentrations were obtained on day 28 and day 32 for the control and PCC 7120\#11 microcosms, respectively (Fig. 3c). The treatment $\times$ time interaction was not significant for Lepadella sp. concentration $\left(F_{(9,81.8)}=1.7985, \quad P=\right.$ $0.0809)$. There was a significant treatment effect for Lepadella sp. concentration $\left(F_{(1,} 16.7\right)=4.8487, \quad P=$ 0.0421; means: control $=5.5$ Lepadella $/ \mathrm{ml}$ and PCC $7120 \# 11=7.7$ Lepadella $/ \mathrm{ml})$. The slope $(0.159$; adjusted $\left.r^{2}=0.914\right)$ of the Lepadella sp. growth curve for the PCC 7120\#11 microcosms was significantly higher $\left(\mathrm{F}_{(1,80)}=4.734, P=0.0325\right)$ than that of the control microcosms (slope $=0.135$; adjusted $r^{2}=0.864$ ) between day 4 and day 25 (the apparent exponential growth phase).

\section{Mosquitocidal activity of PCC 7120\#11}

A single application of PCC $7120 \# 11$ was added to each of the PCC $7120 \# 11$ microcosms on day 7 , at an inmicrocosm concentration $\left(4.5 \times 10^{6}\right.$ cells $\left./ \mathrm{ml}\right)$ that, on the basis of pre-SAM bioassays, should have resulted in approximately $90 \%$ mortality (i.e. an $\mathrm{LC}_{90}$ ) of the third instar An. arabiensis larvae. After the addition of PCC $7120 \# 11, A n$. arabiensis larval mortality on day 8 was $72.3 \pm 4.5 \%$ (mean \pm standard error of the mean; $n=$ 180; 6 replicates of 30 larvae per replicate). A week later (day 15), larval mortality dropped to $17.7 \pm 8.3 \%$. On the remaining evaluation days $(22,29$, and 36$)$, no mortality of the An. arabiensis larvae was observed. An. arabiensis larval mortality was not observed in any of the control microcosms.

\section{Discussion}

In contrast to other larvicides, such as naturally-derived spinosad and the organophosphate temephos, Bti products have little effect on non-target aquatic organisms $[32,33]$. The challenge with the assessment of the ecological impacts of PCC 7120\#11 is that it is in essence an edible delivery vehicle for larvicidal Bti proteins and is a food source for several species of aquatic invertebrates. This means that ecotoxicological and impact assessments of PCC $7120 \# 11$ should ideally assess both the toxicity of the Bti proteins to important test organisms and the effects that a significant increase in a food source may have on the growth and reproduction of these test organisms. The SAM system enables the assessment of both the direct toxicity of PCC 7120\#11 to important aquatic test organisms and potential indirect effects that PCC 7120\#11 may have on the survival, growth and reproduction of the test organisms.

Since one of the advocated advantages of PCC $7120 \# 11$ is that it would multiply and persist in waterbodies and thus reduce the need for repeated treatments $[8,9]$, we performed these experiments using a single inoculation of PCC 7120\#11 to produce an in-microcosm concentration of $4.5 \times 10^{6}$ cells $/ \mathrm{ml}$. The concentration of $4.5 \times 10^{6}$ cells $/ \mathrm{ml}$, which was determined by bioassays in SAMs to be an $\mathrm{LC}_{90}$, was 3.15 -fold higher than the $\mathrm{LC}_{90}$ $\left(1.43 \times 10^{6}\right.$ cells $\left./ \mathrm{ml}\right)$ for An . arabiensis reported for 100 $\mathrm{ml}$ cup assays [14]. The lower $\mathrm{LC}_{90}$ in the cup assays compared to the SAM assays is not unexpected since larvae ingest only PCC $7120 \# 11$ in the cup assays, whereas in the SAMs the ingestion of other PMs and protozoans by the mosquito larvae would likely reduce the relative intake of PCC $7120 \# 11$ cells.

Not unexpectedly, because of the high number of PCC $7120 \# 11$ cells added to the PCC $7120 \# 11$ microcosms on day 7, the effect of treatment on total PM concentration was statistically significant and the concentration of PMs on day 7 was significantly higher in the PCC 7120\#11 microcosms than in the control microcosms. However, since the concentration of PCC 7120\#11 decreased rapidly after day 7 , the concentration of PMs was not statistically different between the two treatment groups on any other day during the experiment. The decrease in the concentration of PCC $7120 \# 11$ between day 7 and day 14 was most probably due to predation of the cells by the invertebrate grazers.

The concentration of inorganic nutrients (nitrate, nitrite, and phosphate) in the control and PCC 7120\#11 microcosms decreased from day 0 (initiation) and was largely depleted by day 20 , as expected due to the utilization of these nutrients by the rapidly growing population of PMs $[19,20,34,35]$. The depletion of the inorganic nutrients coincided with the highest concentration of PMs recorded in the microcosms. The changes 
in the inorganic nutrients are discussed further below in the context of the activities of the different organisms in the microcosms.

Aquatic PMs are efficient in removing phosphate from solution and most of this phosphate is released back into the water upon cell death [36]; e.g. $50 \%$ of particulate phosphate is released into the water as $\mathrm{PO}_{4}-\mathrm{P}$ within a few hours of the onset of autolysis [37]. Since the "sloppy feeding" of grazers (especially daphnids) on PMs damage cells and result in the loss of intracellular components [38], we would expect large amounts of $\mathrm{PO}_{4}-\mathrm{P}$ to be released when invertebrate grazers feed on PMs in the microcosms. In this context, the significantly higher $\mathrm{PO}_{4}$-P concentrations observed in the PCC $7120 \# 11$ microcosms after the addition of PCC 7120\#11 to the microcosms may reflect the release of $\mathrm{PO}_{4}-\mathrm{P}$ from the feeding of the invertebrate grazers on the high concentration of PCC $7120 \# 11$ cells.

Being an excreted waste product, the level of ammonia is expected to increase as the number of invertebrates increase [35], and $\mathrm{NH}_{3}$ has been shown to be the predominant released form of nitrogen for $D$. pulex [39]. However, although the numbers of invertebrates increased in both the control and PCC 7120\#11 microcosms throughout the experiments, the TAN concentrations only started to increase markedly in the microcosms after day 25. The TAN concentrations in the microcosms is likely to be the result of the complex interaction between several processes, including excretion of ammonia by the metazoan consumers [39], and PM-mediated processes such as assimilatory nitrate reduction and dinitrogen fixation by diazotrophic cyanobacteria (including PCC 7120\#11). Since ammonia is preferentially used as an inorganic nitrogen sources by many algae and most cyanobacteria [40, 41], dissolved ammonia would be taken up by PMs and there would be significant intracellular ammonia pools in the PMs [41].

There are two ways that the ammonia could be released by PMs: during growth or due to damage or lysis of cells. Cyanobacteria, and in particular Anabaena spp., have been shown to release ammonia $\left(\mathrm{NH}_{3}\right)$, both in the presence and absence of nitrate in the medium, during different growth phases [40]. Since the ammonia spike (days 11 and 14) in the PCC $7120 \# 11$ microcosms corresponds with the rapid decrease in PCC $7120 \# 11$ cells between days 7 and 14, we postulate that the ammonia spike is primarily due to the release of ammonia from PCC 7120\#11 cells due to "sloppy feeding" by invertebrate grazers. Support for this "sloppy feeding" postulate is provided by the fact that the increase in ammonia in both treatment groups after day 25 corresponds with a rapid and consistent reduction in PMs between days 25 and 35. Since ammonia is a preferred nitrogen source for PMs, we would expect them to rapidly utilize the "extra" ammonia that was available in the PCC $7120 \# 11$ microcosms. The utilization of the "extra" ammonia is suggested by the temporary nature of the day- 14 ammonia peak in the PCC 7120\#11 microcosms. This increased availability of ammonia may also have been, in part, responsible for the slight (not statistically significant) increase, relative to the control microcosms, in PM concentrations for approximately two weeks after the day-14 ammonia spike in the PCC 7120\#11 microcosms.

Ammonia is known to be highly toxic to aquatic invertebrates [42], and may have significant ecological sublethal effects even at low concentrations. Although the TAN concentration was not statistically higher in the PCC7120\#11 microcosms than in the control microcosms, it is important to determine if the TAN levels reached theoretical toxic levels during the temporary, post-inoculation increase in TAN. When considering the most sensitive endpoints, the 2013 Ambient Water Quality Criteria (AWQC) for ammonia document specifies an acute (1-hour average) criterion magnitude and a chronic (30-day rolling average) criterion magnitude for freshwater ecosystems [42]. Since $\mathrm{NH}_{3}$ is substantially more toxic than $\mathrm{NH}_{4}^{+}$and the ratio of $\mathrm{NH}_{3}$ to $\mathrm{NH}_{4}^{+}$increases as the $\mathrm{pH}$ and temperature of the water increases [43], we used the $\mathrm{pH}$ and temperature corrected AWQC to determine if the ammonia levels during the spike on day 14 ( $\mathrm{pH} 7.5$ and $22^{\circ} \mathrm{C}$ ) in the PCC $7120 \# 11$ microcosms would potentially be toxic to highly-sensitive aquatic organisms. However, the post-inoculation TAN spike $(0.595 \mathrm{mg} / \mathrm{l}$ on day 14$)$ in the PCC $7120 \# 11$ microcosms was well below the $\mathrm{pH}$ - and temperature-adjusted values of 7.8 and $1.2 \mathrm{mg}$ TAN/l for the acute criterion and chronic criterion magnitudes, respectively. Although our experiments suggest that treatment of waterbodies with PCC 7120\#11 would not result in toxic levels of $\mathrm{NH}_{3}$, further studies using a range of $\mathrm{pH}$ and temperatures would be useful.

The statistically higher nitrate concentration on day 18 in the PCC $7120 \# 11$ microcosms may also reflect the availability of a preferred nitrogen source (ammonia) during the two measurement periods preceding day 18; i.e. the PMs may have utilized ammonia instead of nitrate, thus resulting in a higher level of nitrate in the PCC 7120\#11 microcosms than in the control microcosms (which did not have the ammonia spike).

The SAM experiments showed that the larvicidal activity of PCC 7120\#11 did not persist in the microcosms after the single inoculation. By day 14, the PCC $7120 \# 11$ concentration was $4.92 \times 10^{5}$ cells $/ \mathrm{ml}$, which is 9.14 -fold lower than the concentration at inoculation $\left(4.5 \times 10^{6}\right.$ cells $/ \mathrm{ml})$. Since PCC $7120 \# 11$ is capable of multiplying in mosquito breeding sites $[8,9]$, the relatively poor persistence of larvicidal activity observed in this study was most likely due to the inability of PCC $7120 \# 11$ to 
replicate in the microcosms at a rate that matched or exceeded their removal by other organisms in the microcosms. In this context, it is important to note that all three types of the metazoan consumers in the microcosms were able to ingest filamentous cyanobacteria (e.g. [26, 27]). The fairly constant concentration of PCC $7120 \# 11$ between days 14 and 28 even though there were logarithmic increases in the non-target invertebrates may, in part, be because PCC $7120 \# 11$ is a filamentous cyanobacterium and the smaller, unicellular algae, such as C. vulgaris, may be more readily consumed by the invertebrates used in this study [44]. The marked reduction in larvicidal activity between days 7 and 14 may not only reflect the reduction by close to a factor of 10 in PCC $7120 \# 11$ concentration during this period but may also be due to the rapid and marked (30.5-fold) increase in the concentration of protozoans (a food source for mosquito larvae) during this period, which may have resulted in fewer PCC $7120 \# 11$ cells being ingested by mosquito larvae. In this light, it is also important to note that there were marked changes in the PCC $7120 \# 11$ microcosms in the ratio of the concentrations of total PMs to PCC 7120\#11 cells between days 7 and 35: day 7, 1.19; day 14, 5.04; day 21, 8.49; day 28, 7.16; day 35, 180.4 (ratios are based on the antilog values of the data presented in Fig. 2a and b). Since the persistence of the larvicidal activity of Bti-based products are affected by several bioenvironmental factors [10], it is reasonable to expect that the persistence of the activity of PCC 7120\#11 would also vary in different habitats. Further research is required to help elucidate the factors that affect PCC $7120 \# 11$ persistence in complex and dynamic aquatic ecosystems which contain a range of non-target invertebrates and particulate food sources.

Although Coleps spp. feed on bacteria and algae [45], the mode of action of larvicidal Bti proteins means that direct toxic effects of PCC $7120 \# 11$ on Coleps spp. are not expected. The population growth profiles of the Coleps sp. were characterized by a rapid increase between days 4 and 14 and a subsequent relatively stable plateau period. The onset of the plateau period corresponds approximately with the depletion of the inorganic nutrients, suggesting that the plateau period is due to nutrient-limiting conditions. Although rotifers and cladocerans (including Daphnia spp.) are predators of protozoans and can suppress ciliates [46, 47], there was no obvious reduction in Coleps sp. populations in either of the treatment groups during the period that $D$. pulex and Lepadella sp. concentrations increased. This suggests that Coleps sp. was either not a preferred prey or that the rate of predation did not exceed the rate of reproduction during the plateau phase.
Since PCC $7120 \# 11$ was present at more than $3.57 \times$ $10^{5}$ cells $/ \mathrm{ml}$ until day 28 , the non-target organisms in the microcosms were exposed to a high PCC 7120\#11 concentration for a period that matched that of the 21day D. magna reproduction test [48]. D. pulex concentrations in the PCC $7120 \# 11$ microcosms were significantly lower than those in the control microcosms on days 18 and 25 and the slope of the D. pulex growth curve for the PCC $7120 \# 11$ microcosms was significantly lower than that of the control microcosms between days 14 and 28 (the last measurement before the apparent onset of the stationary phase). However, by day 32 the mean D. pulex concentration in the PCC $7120 \# 11$ microcosms was statistically identical to that in the control microcosms and when treatment effects were averaged over time there was no statistical difference in mean $D$. pulex concentration between the two treatment groups. This suggests that PCC $7120 \# 11$ temporarily lowered $D$. pulex growth rates, but with growth recovering and there being no long-term effects on $D$. pulex concentrations. The temporarily lowered growth rate may reflect a direct, sub-lethal effect of PCC 7120\#11 on D. pulex, but more likely it reflects an indirect effect, such as a sublethal effect of the ammonia spike in the PCC 7120\#11 microcosms on the growth of $D$. pulex.

There are other ways that PCC 7120\#11 may have reduced the growth rate of $D$. pulex. Large daphnids, such $D$. pulex, can consume a large range of food sources, including small bacteria, ciliates and rotifers [46], and there were thus multiple potential food sources in the microcosms. However, since Daphnia spp. prefer the smaller, unicellular algae such as C. vulgaris [44], it is possible that PCC $7120 \# 11$ is an sub-optimal food source for $D$. pulex and has lower nutritional value than the standard SAM PMs, with the result that $D$. pulex individuals in the PCC 7120\#11 microcosms were unable to match the growth rates of individuals in the control microcosms.

There was no evidence that PCC 7120\#11 caused lethal toxicity to the Lepadella sp. in the PCC 7120\#11 microcosms. This may not only be due to a lack of toxicity of larvicidal Bti proteins to the Lepadella sp. used, but may reflect the fact that rotifers ingest filamentous Anabaena spp. with low efficiency [26], thus possibly preventing exposure to lethal concentrations. The slope of the Lepadella sp. growth curve in the PCC 7120\#11 microcosms between days 4 and 25 was significantly higher than that for the control microcosms and from day 14 onwards the Lepadella sp. concentrations in the PCC $7120 \# 11$ microcosms were higher than those in the control microcosms. Since day 14 corresponds to the post-inoculation spike of ammonia, and to the point at which the D. pulex concentrations in the PCC 7120\#11 microcosms start to be lower than those in the control 
microcosms, it is possible that the higher concentrations of Lepadella sp. in the PCC $7120 \# 11$ microcosms were due to less suppression of Lepadella sp. by $D$. pulex. Daphnia spp. have been shown to suppress rotifers by exploitative competition for shared, limited food resources or by mechanical interference (damage upon attempted ingestion or ingestion) [26].

One of the advantages of PCC $7120 \# 11$ over Bti is that it is able to replicate and persist better in the environment [9], thus providing longer mosquito control and reducing the need for frequent retreatment of waterbodies. From an ecological and regulatory perspective, it would be preferable if the concentration of PCC $7120 \# 11$ reduces after inoculation and if PCC 7120\#11 did not become a well-established member of the PM community in treated waterbodies. In this regard, it is noteworthy that in a period of 4 weeks, PCC $7120 \# 11$ decreased from a concentration of $4.50 \times 10^{6}$ cells $/ \mathrm{ml}$ (at inoculation) to $1.32 \times 10^{3}$ cells $/ \mathrm{ml}$, a more than 3400 fold reduction.

\section{Conclusions}

In this study, PCC $7120 \# 11$ caused small, temporary changes in selected water quality parameters and invertebrate concentrations, but the population growth curves for the non-target invertebrates were surprisingly similar for the two treatment groups. Although shortlived environmental events may have delayed and lasting effects [49], the small, temporary changes observed in the PCC 7120\#11 microcosms should be seen in the context of commonly used mosquito control agents, which are known to be lethal to aquatic invertebrates and significantly affect aquatic diversity $[32,50]$. When considering the relatively minor ecological impacts noted in these experiments and the high larvicidal activity of PCC $7120 \# 11$ against important malaria vectors $[14,15]$, we believe that further evaluation of PCC $7120 \# 11$ as a mosquito larvicide for use in integrated vector management is warranted.

\section{Competing interests}

The authors declare that they have no competing interests.

\section{Authors' contributions}

Conceived the idea: GB. Performed the experiment and analyzed the data: IK and GB. Contributed reagents/materials/analysis tools: GB. Wrote the manuscript: GB and IK. All authors read and approved the final manuscript.

\section{Acknowledgements}

The authors thank M. Coetzee and L.L. Koekemoer (Vector Control Reference Unit, National Institute for Communicable Diseases of the National Health Laboratory Service, Johannesburg, South Africa) for providing the An. arabiensis larvae. The authors express gratitude to A. Zaritsky (Department of Life Science, Ben Gurion University, Israel) for providing Anabaena PCC 7120\#11. This project was partially funded by a National Research Foundation grant awarded to GB. We thank anonymous reviewers for comments that improved this manuscript.
Received: 15 February 2016 Accepted: 27 April 2016

Published online: 10 May 2016

\section{References}

1. Margalit J, Dean D. The story of Bacillus thuringiensis var. israelensis (B.t.i.). J Am Mosq Control Assoc. 1985;1:1-7.

2. Bravo A, Gill SS, Soberón M. Mode of action of Bacillus thuringiensis Cry and Cyt toxins and their potential for insect control. Toxicon. 2007:49:423-35.

3. Bremen JG. The ears of the hippopotamus: manifestations, determinants and estimates of the malaria burden. Am J Trop Med Hyg. 2001;64:1-11.

4. Grard G, Caron M, Mombo IM, Nkoghe D, Mboui Ondo S, Jiolle D, Fontenille D, Paupy C, Leroy EM. Zika virus in Gabon (Central Africa) - 2007: a new threat from Aedes albopictus. PLoS Negl Trop Dis. 2014;8:e2681.

5. Brooke BD, Koekemoer LL. Major effect genes or loose confederations? The development of insecticide resistance in the malaria vector Anopheles gambiae. Parasit Vectors. 2010;3:1-8.

6. Fillinger $U$, Knols BG, Becker N. Efficacy and efficiency of new Bacillus thuringiensis var. israelensis and Bacillus sphaericus formulations against Afrotropical anophelines in Western Kenya. Trop Med Int Health. 2003;8:37-47.

7. Becker N, Rettich F. Protocol for the introduction of new Bacillus thuringiensis israelensis products into the routine mosquito control program in Germany. J Am Mosq Control Assoc. 1994;10:527-33.

8. Boussiba S, Wu X-Q, Ben-Dov E, Zarka A, Zaritsky A. Nitrogen-fixing cyanobacteria as gene delivery system for expressing mosquitocidal toxins of Bacillus thuringiensis ssp. israelensis. J Appl Phycol. 2000;12:461-7.

9. Manasherob R, Otieno-Ayayo ZN, Ben-Dov E, Miaskovsky R, Boussiba S, Zaritsky A. Enduring toxicity of transgenic Anabaena PCC 7120 expressing mosquito larvicidal genes from Bacillus thuringiensis subsp. israelensis. Environ Microbiol. 2003;5:997-1000.

10. Mittal PK. Biolarvicides in vector control: challenges and prospects. J Vector Borne Dis. 2003:40:20-32.

11. Yap WH, Thanabalu T, Porter AG. Influence of transcriptional and translational control sequences on the expression of foreign genes in Caulobacter crescentus. J Bacteriol. 1994;176:2603-10.

12. Kurmayer $R$, Jüttner F. Strategies for the co-existence of zooplankton with the toxic cyanobacterium Planktothrix rubescens in Lake Zürich. J Plankton Res. 1999:21:659-83.

13. Xiaoqiang W, Vennison SJ, Huirong L, Ben-Dov E, Zaritsky A, Boussiba S. Mosquito larvicidal activity of transgenic Anabaena strain PCC 7120 expressing combinations of genes from Bacillus thuringiensis subsp. israelensis. Appl Environ Microbiol. 1997:63:4971-4.

14. Ketseoglou I, Bouwer G. The susceptibility of five African Anopheles species to Anabaena PCC 7120 expressing Bacillus thuringiensis subsp. israelensis mosquitocidal cry genes. Parasit Vectors. 2012;5:220-4.

15. Lluisma AO, Karmacharya N, Zarka A, Ben-Dov E, Zaritsky A, Boussiba S. Suitability of Anabaena PCC 7120 expressing mosquitocidal toxin genes from Bacillus thuringiensis subsp. israelensis for biotechnological application. Appl Microbiol Biotechnol. 2001;57:161-6.

16. Ketseoglou I, Bouwer G. Optimization of photobioreactor growth conditions for a cyanobacterium expressing mosquitocidal Bacillus thuringiensis Cry proteins. J Biotechnol. 2013;167:64-71.

17. Giddings $G$. The release of genetically engineered microorganisms and viruses in the environment. New Phytol. 1998;140:173-84.

18. Stephenson JR, Warnes A. Release of genetically modified micro-organisms into the environment. J Chem Technol Biotechnol. 1996;65:5-14.

19. Meador JP, Taub FB, Sibley TH. Copper dynamics and the mechanism of ecosystem level recovery in a standardized aquatic microcosm. Ecol Appl. 1993:3:139-55.

20. Taub FB. Standardized aquatic microcosm: development and testing. In: Boudou A, Ribeyre F, editors. Aquatic ecotoxicology: Fundamental concepts and methodologies, vol. 1. Boca Raton: CRC Press; 1989. p. 47-92.

21. Taub FB. Unique information contributed by multispecies systems: examples from the standardized aquatic microcosm. Ecol Appl. 1997;7:1103-10.

22. Coetzee M, Craig M, Le Sueur D. Distribution of African malaria mosquitoes belonging to the Anopheles gambiae complex. Parasitol Today. 2000;16:74-7.

23. Snell TW, Janssen CR. Rotifers in ecotoxicology: a review. Hydrobiologia. 1995; 313:231-47

24. Havel J, Talbott B. Life history characteristics of the freshwater ostracod Cyprinotus incongruens and their application to toxicity testing. Ecotoxicology. 1995:4:206-18. 
25. Martins J, Oliva Teles L, Vasconcelos V. Assays with Daphnia magna and Danio rerio as alert systems in aquatic toxicology. Environ Int. 2007;33:414-25.

26. Gilbert JJ, Durand MW. Effect of Anabaena flos-aquae on the abilities of Daphnia and Keratella to feed and reproduce on unicellular algae. Freshwater Biol. 1990;24:577-96.

27. Grant IF, Egan EA, Alexander M. Measurement of rates of grazing of the ostracod Cyprinotus carolinensis on blue-green algae. Hydrobiologia. 1983;106:199-208.

28. ASTM. ASTM E1366-02: Standard practice for standardized aquatic microcosms: Fresh water. West Conshohocken: ASTM International; 2002.

29. Zar JH. Biostatistical analysis. 4th ed. Upper Saddle River: Prentice Hall; 1999.

30. Bartlett MS. The use of transformations. Biometrics. 1947;3:39-52.

31. Kenward MG, Roger $J H$. Small sample inference for fixed effects from restricted maximum likelihood. Biometrics. 1997:53:983-97.

32. Marina CF, Bond JG, Muñoz J, Valle J, Novelo-Gutiérrez R, Williams T. Efficacy and non-target impact of spinosad, Bti and temephos larvicides for control of Anopheles spp. in an endemic malaria region of southern Mexico. Parasit Vectors. 2014;7:55.

33. Lacey LA. Bacillus thuringiensis serovariety israelensis and Bacillus sphaericus for mosquito control. J Am Mosq Control Assoc. 2007;23:133-63.

34. Taub FB, Kindig AC, Meador JP, Swartzman GL. Effects of "seasonal succession" and grazing on copper toxicity in aquatic microcosms. Verh Internat Verein Limnol. 1991:24:2205-14.

35. Tsirtsis G, Karydis M. Aquatic microcosms: a methodological approach for the quantification of eutrophication processes. Environ Monit Assess. 1997; 48:193-215.

36. Golterman HL. The Phosphate Cycle. In: Golterman HL, editor. Physiological Limnology: An approach to the physiology of lake ecosystems. Amsterdam: Elsevier Scientific Publishing; 1975. p. 87-98.

37. Golterman HL. Studies on the cycle of elements in fresh water. Acta Bot Neerl. 1960;9:1-58.

38. Lampert W. Release of dissolved organic carbon by grazing zooplankton. Limnol Oceanogr. 1978;23:831-4.

39. Jacobsen TR, Comita GW. Ammonia-nitrogen excretion in Daphnia pulex. Hydrobiologia. 1976;51:195-200.

40. Boussiba S, Gibson J. Ammonia translocation in cyanobacteria. FEMS Microbiol Rev. 1991;88:1-14.

41. Ritchie RJ. The ammonia transport, retention and futile cycling problem in cyanobacteria. Microb Ecol. 2013;65:180-96.

42. US EPA. Aquatic life ambient water quality criteria for ammonia - Freshwater 2013. Washington: U.S. Environmental Protection Agency; 2013.

43. Emerson K, Russo RC, Lund RE, Thurston RV. Aqueous ammonia equilibrium calculations: effects of pH and temperature. J Fish Res Board Can. 1975;32: 2379-83.

44. Haney JF. Field studies on zooplankton-cyanobacteria interactions. N Z J Mar Freshwater Res. 1987;21:467-75.

45. Buonanno F, Anesi A, Guella G, Kumar S, Bharti D, La Terza A, Quassinti L, Bramucci M, Ortenzi C. Chemical offense by means of toxicysts in the freshwater ciliate, Coleps hirtus. J Eukaryot Microbiol. 2014;61:293-304.

46. Pace ML, Vaqué $\mathrm{D}$. The importance of Daphnia in determining mortality rates of protozoans and rotifers in lakes. Limnol Oceanogr. 1994:39:985-96.

47. Jack JD, Gilbert JJ. Effects of metazoan predators on ciliates in freshwater plankton communities. J Eukaryot Microbiol. 1997;44:194-9.

48. OECD. Test No. 211: Daphnia magna Reproduction Test, OECD Guidelines for the Testing of Chemicals, Section 2. Paris: OECD Publishing; 2012.

49. Matthews RA, Landis WG, Matthews GB. The community conditioning hypothesis and its application to environmental toxicology. Environ Toxicol Chem. 1996:15:597-603.

50. Day KE. Acute, chronic and sublethal effects of synthetic pyrethroids on freshwater zooplankton. Environ Toxicol Chem. 1989:8:411-6.

\section{Submit your next manuscript to BioMed Central and we will help you at every step:}

- We accept pre-submission inquiries

- Our selector tool helps you to find the most relevant journal

- We provide round the clock customer support

- Convenient online submission

- Thorough peer review

- Inclusion in PubMed and all major indexing services

- Maximum visibility for your research

Submit your manuscript at www.biomedcentral.com/submit
Biomed Central 